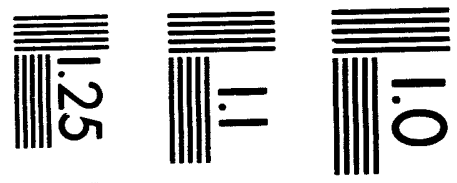

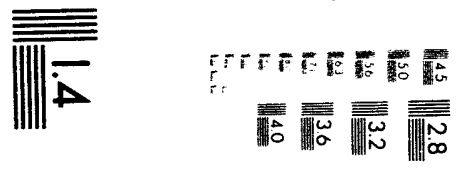

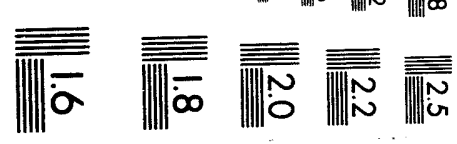



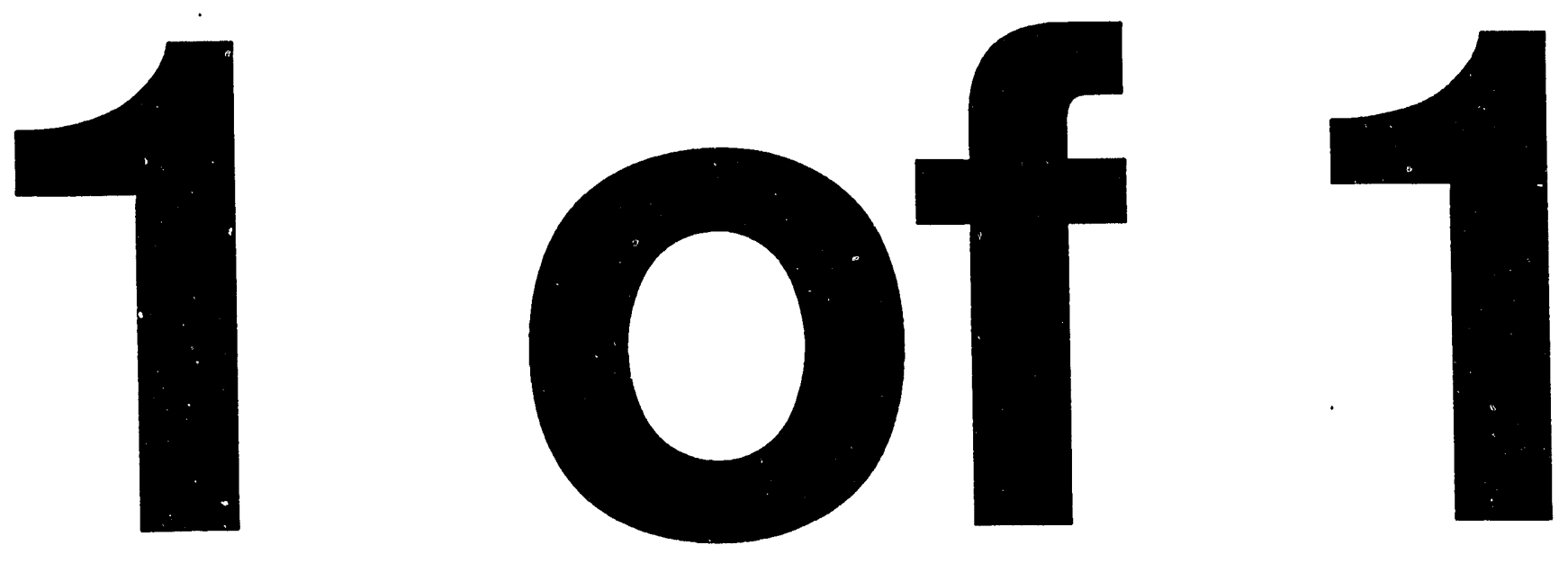
ORNL/ER/Sub/87-99053/62

Energy Systems Environmental Restoration Program ORNL Environmental Restoration Program

\section{Data Base Management Plan for the Remedial Investigation of Waste Area Grouping 10, Operable Unit 3, at Oak Ridge National Laboratory, Oak Ridge, Tennessee}

Date Issued-October 1993

Prepared by

Bechtel National, Inc.

Oak Ridge, Tennessee

under subcontract 12B-99053C

Prepared for

U.S. Department of Energy

Office of Environmental Restoration and Waste Management under budget and reporting code EW 20

OAK RIDGE NATIONAL LABORATORY

Oak Ridge, Tennessee 37831-6285 managed by

MARTIN MARIETTA ENERGY SYSTEMS, INC. for the

U.S. DEPARTMENT OF ENERGY under contract DE-AC05-84OR21400 


\section{2}

\section{DATa baSE MANAgEMENT PLAN}

FOR THE

REMEDIAL INVESTIGATION OF WASTE AREA GROUPING 10,

OPERABLE UNIT 3, AT

OAK RIDGE NATIONAL LABORATORY, OAK RIDGE, TENNESSEE

Bechtel Job 19118

REV.: 0 DATE: $10 / 27 / 93$

CONCURRENCE:

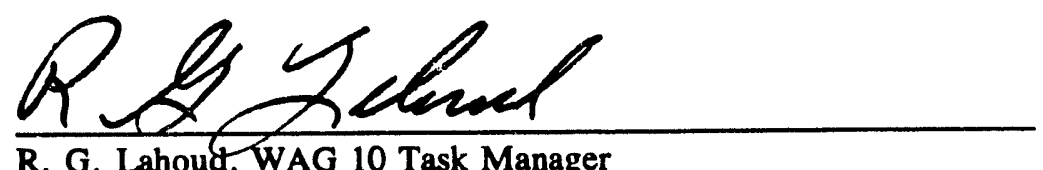

R. G. Lahoud, WAG 10 Task Manager

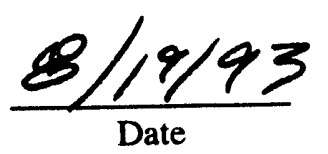

CONCURRENCE: CRohman

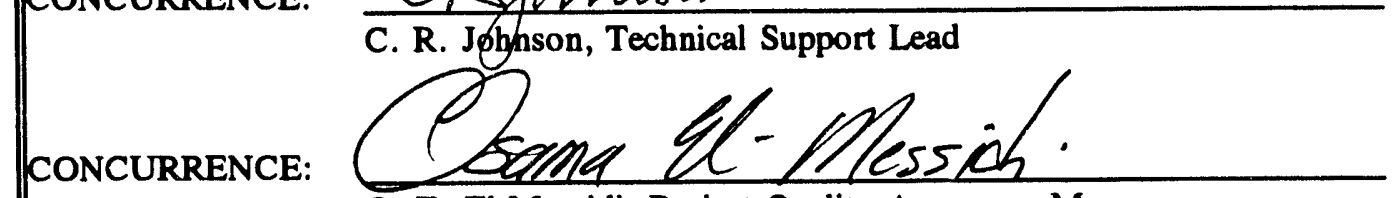

O. E. El-Messidi, Project Quality Assurance Manager

CONCURRENCE:

APPROVED BY:

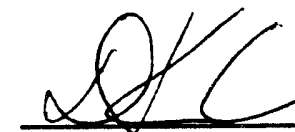

D. K. Cowser, Operations Manager

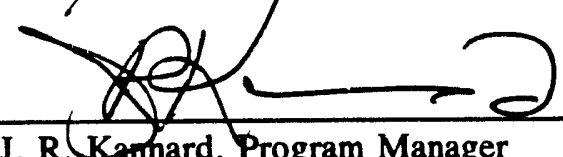

J. R. Kannard, Program Manager

CONCURRENCE:

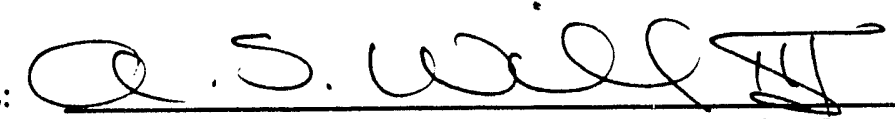

A. S. Will III, ORNL Environmental Restoration Program

RI/FS Project Manager

CONCURRENCE:

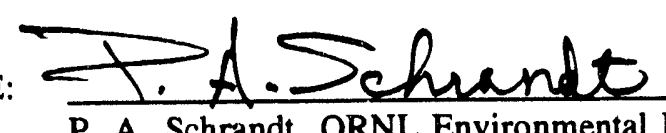

P. A. Schrandt, ORNL Environmental Restoration Division

Quality Assurance Specialist

CONCURRENCE:
Leachterk

L. A. Hook, ORNL Environmental Sciences Division ORNL RI/FS Data Base Manager
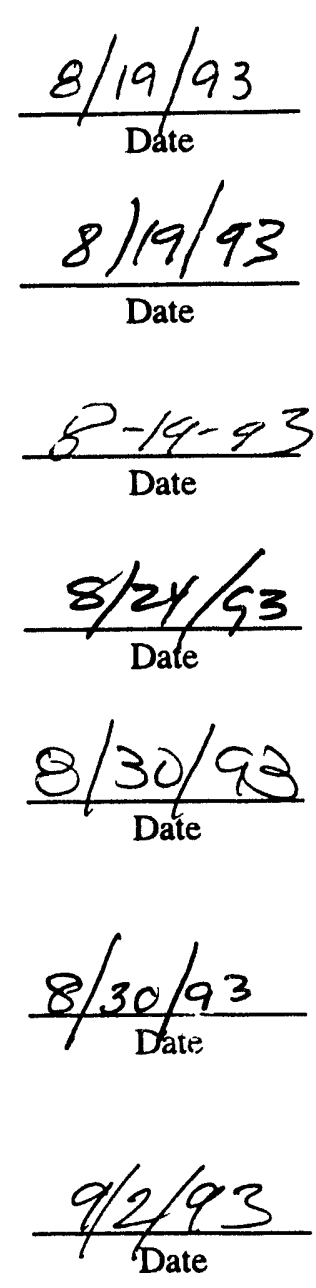


\section{CONTENTS}

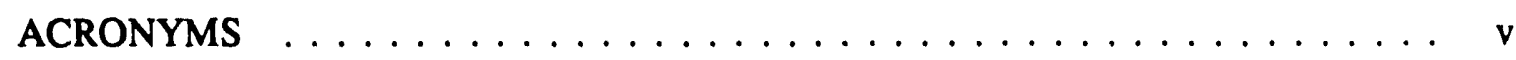

EXECUTIVE SUMMARY $\ldots \ldots \ldots \ldots \ldots \ldots \ldots \ldots \ldots$ vii

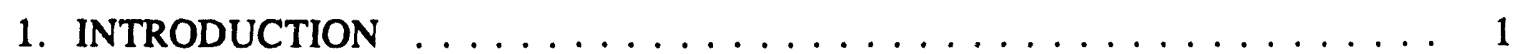

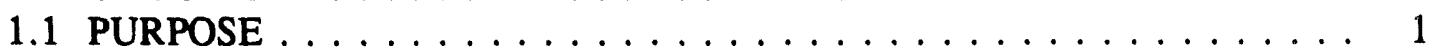

1.2 BACKGROUND $\ldots \ldots \ldots \ldots \ldots \ldots \ldots$

2. DATA COLLECTION $\ldots \ldots \ldots \ldots \ldots \ldots \ldots \ldots \ldots \ldots$

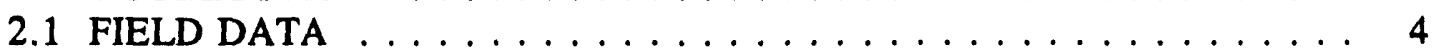

2.2 ANALYTICAL DATA $\ldots \ldots \ldots \ldots \ldots \ldots \ldots$

2.2.1 Close Support Laboratory Data . . . . . . . . . . . . . . . 6

2.2.2 Analytical Subcontractor Laboratory Data . . . . . . . . . . . 6

2.3 HISTORICAL DATA . . . . . . . . . . . . . . . . 6

3. DATA BASE CONTENT $\ldots \ldots \ldots \ldots \ldots \ldots \ldots \ldots$

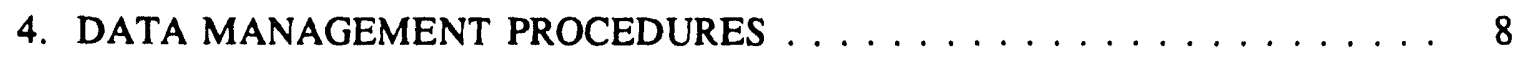

REFERENCES AND PERTINENT PROJECT PROCEDURES . . . . . . . . . . . 9 


\section{ACRONYMS}

CSL Close Support Laboratory

DOE U.S. Department of Energy

OREIS Oak Ridge Environmental Information System

ORNL Oak Ridge National Laboratory

OU operable unit

P\&A plugging and abandonment

PDCC Project Document Control Center

PP project procedure

RI remedial investigation

RI/FS remedial investigation/feasibility study

TM technical memorandum

WAG waste area grouping 


\section{EXECUTIVE SUMMARY}

This Data Base Management Plan describes the gathering, verifying, analyzing, reporting, and archiving of data generated during the remedial investigation of Waste Area Grouping 10, Operable Unit 3. This investigation will produce data documenting wellhead surveys, well headspace gas pressure measurements, geophysical surveys, water level measurements, and borehole geophysical logs. Close Support Laboratory analyses will be performed on well headspace gas and well water samples.

The 1500 series Bechtel Project Procedures, "Data Base Management," and the project Data Base Management Plan will be used in conjunction with this plan to ensure that data are handled properly. 


\section{INTRODUCTION}

\subsection{PURPOSE}

The remedial investigation (RI) of Waste Area Grouping (WAG) 10, Operable Unit (OU) 3 will involve gathering, verifying, analyzing, reporting, and archiving numerous types of field and analytical data. Field investigations will produce data documenting wellhead evaluation surveys, civil surveys, surface geophysical surveys, well headspace pressure measurements, water level measurements, and borehole geophysical logging. Figure 1 is a schematic of the flow of data from the field to the data base. Close Support Laboratory (CSL) analyses will be performed on well water and well headspace samples collected during field investigations. Samples taken during the OU3 effort will be used for waste management and health and safety purposes. Data quality objectives established for OU3 require Level 2 data. All data from these activities will be incorporated into Bechtel's Remedial Investigation/Feasibility Study (RI/FS) Project data base and will be managed in accordance with the RI/FS Data Base Management Plan and this WAG-specific plan.

Environmental data gathered during this investigation will be used to develop a strategy for entering the well, to determine the genesis of any gases or of potentially dangerous wellhead pressure, to determine the risks of opening or lowering investigative tools into the well, and to develop a strategy for handling investigation-derived wastes during the eventual plugging/abandonment of the wells. The sampling strategy was not developed to be used as part of any regulatory compliance sampling, data collection, analysis, validation, or data handling processes. The WAG 10 data will be collected to satisfy Level 2 .

\subsection{BACKGROUND}

WAG 10 is the subsurface component of the hydrofracture sites at Oak Ridge National Laboratory (ORNL). The hydrofracture process was a unique waste disposal method for approximately 3.2 million gallons of low-level radioactive wastes containing an aggregate of approximately 1.4 million curies of radioactivity over a 25 -year period (1959-1984). The technology involved injecting waste materials mixed with grout and additives under pumping pressures of 2000 psi or greater into a deep, low-permeability shale formation. The injected slurry spread along fractures and bedding planes for hundreds of feet from the injection points, forming thin grout sheets.

Four sites in Melton Valley were used in the development and full-scale application of hydrofracture operations. WAG 10 comprises the underground component of the four sites (i.e., wells, injected grout sheets, and contaminated media). The Federal Facility Agreement for the Oak Ridge Reservation identifies WAG 10 as:

- DOE No. X10.0001: Hydrofracture Experiment Site 1 (HF-1),

- DOE No. X10.0002: Hydrofracture Experiment Site 2 (HF-2),

- DOE No. X10.0003: Old Hydrofracture Facility (OHF) (also known as HF-3), and

- DOE No. X10.0004: New Hydrofracture Injection Well (NHF) (also known as HF-4). 


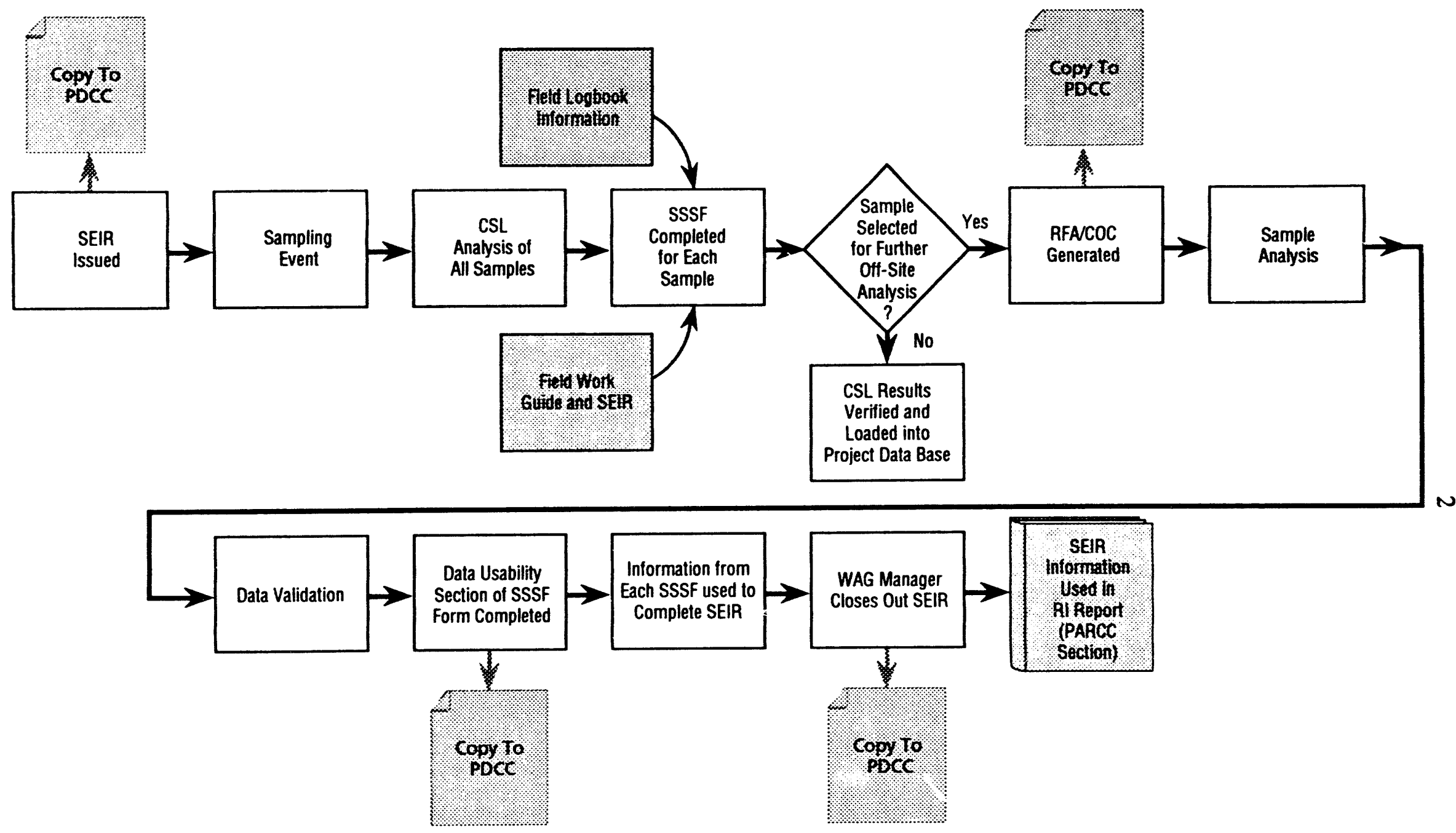

Fig. 1. WAG 10 data flow schematic. 
To manage the environmental restoration of WAG 10, the U.S. Department of Energy (DOE) has divided the WAG into three OUs:

- OU1: grout sheets,

- OU2: groundwater, and

- OU3: wells and boreholes.

DOE's strategy calls for resources to be applied initially to OU3, with the objective of conducting plugging and abandonment (P\&A) operations for as many as possible of the approximately 100 existing WAG 10 wells and boreholes. This Data Base Management Plan specifies data management protocols for activities that will be conducted as part of the OU3 investigation, which is described in the revised WAG 10 Field Sampling Plan.

The investigation of OU3 will begin with a wellhead evaluation survey, which will involve locating and preparing as-built drawings for each wellhead. On the basis of this information, a field work guide will be developed for tapping the wells and measuring well headspace pressures. A well headspace gas sample will then be collected at each well, and the samples will be analyzed at the Close Support Laboratory (CSL).

Based on the results of the pressure measurements and well evaluation survey, water in as many wells as possible will be sampled to assess water quality and to allow scoping of waste management issues during well P\&A. Approximately three grab samples will be collected from each well; all samples will be analyzed at the CSL.

When well water sampling and analysis are completed, as many wells as feasible will be geophysically logged to develop an understanding of the downhole configuration of each well (e.g., cased and uncased intervals and screened intervals). A seismic reflection survey will be conducted concurrently to locate a tear fault that may exist near the hydrofracture sites. The data derived from these activities will be documented in technical memoranda (TMs) and will be summarized in the RI Report. 


\section{DATA COLLECTION}

\subsection{FIELD DATA}

Data from WAG 10 field activities will be collected electronically, in logbooks, and on standard data collection forms as described in Bechtel Project Procedures (PPs) 1501, "Data Collection, Coding, and Entry"; 1631, "Logbook Protocols"; and 1637, "Field Data Acquisition Forms." Data recorded on standard forms will be reviewed and checked by technical specialists and entered into data base tables. Data entry will be verified either through $100 \%$ comparison with the data entry forms or through double entry. (Double entry consists of two different people entering data from the entry form into the data base. The two data files are then compared electronically to detect discrepancies.) Discrepancies will be resolved by reviewing the original data collection form or reference logbook and, if necessary, consulting the responsible data gatherer or reviewer.

Electronic data (e.g., seismic reflection data) will be transferred from floppy disks to Bechtel's VAX cluster and loaded into appropriate WAG-specific ORACLE tables using ORACLE's SQLLOAD, PL/SQL, or PRO*C capabilities or a combination of these utilities, depending on the volume and/or validation requirements of the data. The use of SQLLOAD, $\mathrm{PL} / \mathrm{SQL}$, or PRO*C is determined by the format of the electronic deliverable, as opposed to the type of data validation to be done. Most of the data will be in Contract Laboratory Program (CLP) format, and PRO*C will be used to load into tables that can be used to review/evaluate the data. Preliminary checks for errors and reasonableness will be performed on raw data by the responsible group identified in Table 1 before transfer to the data base. Error checking routines and error logging inherent in communications and ORACLE's software will be performed as data are loaded into ORACLE. Finally, data verification will be completed by providing data base output to technical specialists designated as reviewers by the WAG 10 Task Manager. Appropriate validation codes (as defined in PPs 1501 and 1501.1, "Characterization Data Base") will be provided by the reviewer and added to each data record.

Collection of well headspace gas and well water data will be recorded in the field with bar code readers. Bar code menus have been established for container preparation, sample tracking, container transfer, and sample disposition and archiving. The bar code readers will be operated and maintained in accordance with PP 1603.1, "Intermec 9460 Bar Code Reader User's Procedure."

\subsection{ANALYTICAL DATA}

Analytical data for most ORNL RI/FS activities are provided by the CSL and the Analytical Subcontractor Laboratory. For OU3 investigations specified in the revised WAG 10 Sampling and Analysis Plan, only CSL analyses will be performed. However, offsite analyses may be required during the OU3 RI due to a change in strategy or discoveries during the investigation. The following paragraphs address both types of analytical data. 
Table 1. WAG 10 data base content

Data type

Data type code

Responsible group

Civil survey

Topographic maps

SSV101

Engineering

Well/piezometer locations and elevations

SSV104

Sampling point locations

SSV105

Geophysical surveys

Electromagnetic conductivity

Seismic reflection

SSV201/201A

Geotechnical

Boring and well data

Well construction logs

Geophysical well logs

SSV301

HYG102/102A

HYG105

Geotechnical

Field water level measurements

HYG301/301A

Geotechnical

Groundwater sampling records

HYG701

Geotechnical

Radiological and chemical data

CON101

Analytical

Well headspace pressure

CON101

Engineering 


\subsubsection{Close Support Laboratory Data}

Management of CSL data is governed by PP 1726, "Transfer of CSL Data into Project Records," and PP 1727, "Reporting of CSL Analytical Results." In accordance with these procedures, hard-copy results of all data forms or relevant logbooks will be transmitted to the Project Document Control Center (PDCC) within one calendar month after all analyses requested during a sampling event are completed. Electronic data corresponding to the hard-copy data will be generated at the CSL, reviewed and checked by the CSL Supervisor in accordance with PP 1727, Sect. 5, and transmitted to the Data Base Supervisor for inclusion in the RI/FS data base main ORACLE CSL data table. CSL data in the RI/FS data base may be changed only if a data base change request is signed by the CSL Supervisor and the Data Base Supervisor.

\subsubsection{Analytical Subcontractor Laboratory Data}

Fixed laboratory analytical results will be received in both hard-copy data packages and on floppy disks. Data files will be uploaded to Bechtel's VAX cluster and transferred to appropriate WAG 10 ORACLE tables using ORACLE's SQLLOAD, PL/SQL, or PRO*C capabilities or a combination of these utilities (depending on the volume and/or validation requirements of the data). Data will then be verified by comparing the electronic results with the hard-copy data package and with chain-of-custody data resident in the project sample tracking (bar code) data base. If an exac: correspondence does not occur, research will be initiated to define and resolve discrepancies, and, if necessary, the laboratory will be asked to resubmit the data.

After each data package has been verified and the corresponding electronic file has been completed, the data will be transferred (in both hard-copy and electronic format) to technical data reviewers. Validation will be performed in accordance with U.S. Environmental Protection Agency guidelines and project procedures and documented on the hard copy; appropriate qualification and validation codes will be entered into the electronic file. Complete, validated data packages and data files will be verified by comparing the electronic file with the hard copy containing validation codes. Validated files will replace the original unvalidated data in the comprehensive analytical results ORACLE table, and validated data packages will be retained in PDCC. Error checking and completeness verification will be performed on all data replacements.

\subsection{HISTORICAL DATA}

Data transferred to Bechtel's data base from ORNL's existing data base will be verified in accordance with PP 1502, "Verification of Existing Data," and stored in an ORACLE table before being used by project personnel. Historical data will be traceable by source supplier identification in the text, figure, or table where it is used to the extent that the Bechtel Team is able to identify the source. ORNL and Bechtel data will be merged as necessary and according to appropriate data types defined in PP 1501.1 whenever combined data are to be used in producing technical documents. Merged files will be supplied to ORNL's Oak Ridge Environmental Information System (OREIS) after completion of the corresponding TMs or the RI Report, as appropriate. 


\section{DATA BASE CONTENT}

Anticipated sources of data associated with OU3 field and laboratory activities are listed by data type code in Table 1. Full data base content and format listing for each data type can be found in PP 1501.1; master tables defining coded values for various data fields are provided in PP 1501.

Engineering applications that require data from the data base (particularly figures generated for reports) will use data resident in project data base tables. Data will be transferred to graphics workstations either in ASCII or ORACLE format. (RI data such as analytical data on maps and figures will be under the control of the Data Base Group, but the Engineering Group will be responsible for the preparation and submittal of maps and figures.)

Bechtel drawing 19118-99-SK-01 illustrates data collection and transfer throughout RI/FS activities. Table 1 lists specific data types associated with anticipated field investigations relevant to WAG 10 scheduled activities. 


\section{DATA MANAGEMENT PROCEDURES}

Bechtel's RI/FS data base for WAG 10 will be compatible with OREIS. Environmental data will be stored in ORACLE tables and will be converted to ORACLE export formats for transfer to OREIS. Supporting documentation, including data collection, transfer, change request, and validation forms, will be stored in PDCC to provide an audit trail for tracking environmental data base content. Raw data can be in a number of formats, including bar code reader files, laboratory and field instrumentation log files, spreadsheets, and a variety of encrypted (software-dependent) coded files. Project personnel health and safety information, document control, laboratory sample analysis tracking, engineering, and project management data bases are maintained separately and are explained in appropriate project procedures and in the project Data Base Management Plan. Data received from ORNL will be tracked by PDCC and included in project data base tables (as explained in Sect. 2.3).

Access to data is controlled by PP 1501. Verified data can be changed (and changes tracked and approved) only by using "Data Base Change Request" forms. The individual making a request will not also make the change. Similarly, data can be output only when approved "Data Base Request for Services" forms are submitted and processed.

Field sample collection and handling are controlled by PPs ' 103 , "Sample Information Management System"; 1603.1, and 1637. Intermec bar code readers are used to provide electronic chain of custody and sampling event information. Logbook entries and "Request for Analysis" forms (maintained in accordance with separate project procedures) are used to verify bar code information. Bar code reader contents are uploaded daily to the RI/FS Field Office Facility computer system and to ORACLE tables. Data gatherers are required to verify reader contents frequently, and necessary changes are authorized and controlled through "Data Base Change Request" forms submitted to the Data Base Manager.

Bechtel's VAX cluster is the centralized storage location for project data, and PDCC houses all supportive documentation. Daily backup of all data is performed by Bechtel's Automation Technology Department, which is responsible for system management. All data are copied weekly to magnetic tape and stored off site. System access is controlled by user name/password and by specific directory and file protection levels determined by project staff. Backup and system access control are explained in "Automation Technology Procedures and Standards." ORACLE use requires another level of user name/password and specific privileges for table access, again determined by project staff. Training for each data base management position is defined, administered, and documented in accordance with PP 1120, "Administration of RI/FS Training." The Data Base Supervisor will identify and supervise the personnel who have received the proper training and have demonstrated competence to modify or make additions to data base tables. 


\section{REFERENCES AND PERTINENT PROJECT PROCEDURES}

Data Base Management Plan for the Remedial Investigation/Feasibility Study at Oak Ridge National Laboratory, Oak Ridge, Tennessee, Bechtel National, Inc., ORNL/ER/Sub/8799053/2/R1, Oak Ridge, Tenn.

Remedial Investigation Implementation Plan for Waste Area Grouping 10 at Oak Ridge National Laboratory, Oak Ridge, Tennessee, Vol. 2, Bechtel National, Inc., ORNL/ER/Sub/87-99053/6/V2, Oak Ridge, Tenn.

"Automation Technology Procedures and Standards," Bechtel National, Inc., Oak Ridge, Tennessee.

Bechtel Project Procedure 1120, "Administration of RI/FS Training"

Bechtel Project Procedure 1501, "Data Collection, Encoding, and Entry"

Bechtel Project Procedure 1501.1, "Characterization Data Base"

Bechtel Project Procedure 1502, "Verification of Existing Data"

Bechtel Project Procedure 1603, "Sample Information Management System"

Bechtel Project Procedure 1603.1, "Intermec 9460 Bar Code Reader User's Procedure"

Bechtel Project Procedure 1631, "Logbook Protocols"

Bechtel Project Procedure 1637, "Field Data Acquisition Documentation"

Bechtel Project Procedure 1726, "Transfer of CSL Data into Project Records"

Bechtel Project Procedure 1727, "Reporting of CSL Analytical Results" 


\section{DISTRIBUTION}

1. H. L. Boston

2. C. D. Goins

3. L. A. Hook

4. L. W. Little

5-8. D. M. Matteo

9-10. P. T. Owen

11. P. A. Schrandt

12. A. S. Will

13. P. S. Wood

14. Central Research Library

15-17. ORNL ER Document Management Center-RC

18-20. Central ER Document Management Center

21. Laboratory Records Dept.

22. ORNL Patent Section

23. Office of Assistant Manager for Energy Research and Development, DOE Oak Ridge Operations Office, P.O. Box 2001, Oak Ridge, TN 37831-8600

24. J. R. Kannard, Program Manager, Bechtel National, Inc., P.O. Box 350, Oak Ridge Corporate Center, 151 LaFayette Drive, Oak Ridge, TN 37830

25. D. W. Swindle, Radian Corporation, 120 South Jefferson Circle, Oak Ridge, TN 37830

26-27. Office of Scientific and Technical Information, P.O. Box 62, Oak Ridge, TN 37831 


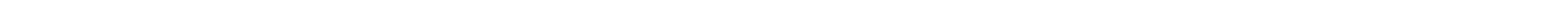


